\title{
Síndrome de Lemierre, la enfermedad olvidada
}

D. Insignares, D. Severiche, G. Sanchez, A. Uribe, F. Varón

Universidad de La Sabana / Fundación Neumológica Colombiana

\section{INTRODUCCIÓN}

El síndrome de Lemierre es una tromboflebitis séptica de la vena yugular como complicación de una bacteriemia por anaerobios. Usualmente se desarrolla en pacientes con faringitis y suele ser por Fusobacterium necrophorum.

Esta entidad suele presentar embolización séptica en especial a los pulmones por lo cual no es infrecuente que los pacientes desarrollen dificultad respiratoria comportándose como neumonía o sindrome de dificultad respiratoria del adulto.

\section{OBJETIVO}

Describir las manifestaciones clínicas, acercamiento diagnostico y manejo de un paciente con síndrome de Lemierre.

\section{REPORTE DE CASO}

Paciente masculino de 27 años, sin antecedentes, con cuadro clínico de una semana de evolución de odinofagia, fiebre y escalofrió. Como diagnóstico inicial se planteo amigdalitis. No obstante, una semana después sintomatologia se exacerba, reconsulto al servicio de urgencias donde se realizo el diagnostico de neumonía. Presenta falla respiratoria aguda hipoxemica asociado a choque séptico. Se realizo una tomografía de tórax que mostro múltiples lesiones nodulares en parénquima pulmonar; hemocultivos con presencia de Fusobacterium nucleatum. Durante su estancia en $\mathrm{UCl}$, al exámen físico se encontró una masa blanda en el lado izquierdo del cuello, se solicitó angiotomografia que reportó trombosis de la vena yugular interna. Teniendo en cuenta contexto clínico y hallazgos angiotomográficos se considero paciente un sindrome de Lemierre, se completo el manejo antibiótico y se inicio anticoagulación plena. El paciente presento evolución clínica favorable con posterior egreso.

\section{CONCLUSIONES}

El sindrome de Lemierre descrito por primera vez en 1936 por André Lemierre es una tromboflebitis séptica de la vena yugular como complicación de infecciones de cabeza y cuello. El germen implicado más frecuente es el Fusobacterium necrophorum. La sospecha clínica asociado a un diagnóstico oportuno podría prevenir las complicaciones entre las que se encuentra con mayor frecuencia la embolización séptica a pulmones.

\section{MÉTODOS}

Reporte de un caso de un paciente con sindrome de Lemierre en la Unidad de Cuidado Intensivo Médico de la Fundación Cardioinfantil de Bogotá

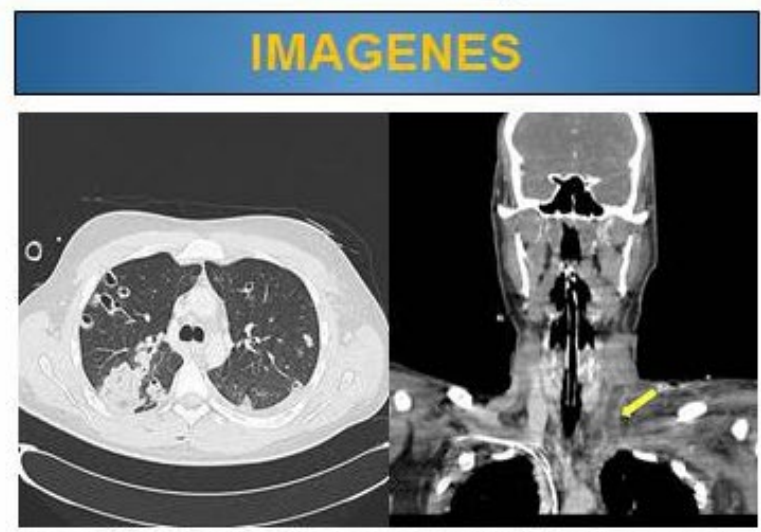

Imagen 1. TAC Tórox: Opacidades de Imagen 2. TAC cuello controstado: cocupación alveolar en lóbulos Defecto de lenamiento concéntrioo a superiores y segmento basal posterior lo largo de toda la vena yugular derecho compatibles con proceso interna izquierda infeccioso multiobar $y$ signos de infeccioso multiobar y signos de abscedación, asociado a nódulio pulmonares pulmonares

\section{REFERENCIAS}

1. Janda Riordan T. Human infection with Fusobacterium necrophorum (Necrobacillosis), with a focus on Lemierre's syndrome. Clin Microbiol Rev. $2007 ; 20(4):$ p. $622-59$.

2. Kuppali K, Livorsi D, Talati NJ, Osborn M. Lemierre's syndrome due to Fusobacterium necrophorum. Lancet Infect Dis. 2012; 12(10): p. 808-15.

3. Lemierre A. On certain septicemias due to anaerobic organisms. Lancet. Lemiente A. On cert

4. Holm K, Svensson PJ. Rasmussen M. Invasive Fusobacterium necrophorum infections and Lemierre's syndrome: the role of thrombophilia and EBV. European Journal of Clinical Microbiology \& Infectious Diseases. 2015; 34(11): p. 2199-2207.

5. Centor RM, Atkinson TP, Ratlff AE, Xiao L, Crabb DM. Estrada CA, et al. The Clinical Presentation of Fusobacterium Positive and StreptococoalPositive Pharyngitis in a University Health Clinc. Annals of Interna Medicine. 2015; 184(4): p. 241 